\section{Technical Difficult Subarach- noid Block in a Morbidly Obese Patient: Ultrasound Guidance and Improvisation is the Key to Success}

Sir,

Subarachnoid block (SAB) in obese patients is challenging due to obscured anatomical landmark. We report one such case of a morbidly obese gentleman, when use of ultrasound (USG) and an improvisation of the technique helped us for a successful spinal pucture forSAB.

A 21-year, $105 \mathrm{Kgs}$ (body mass index $40.38 \mathrm{Kg} / \mathrm{m}^{2}$ ), man was posted for anterior cruciate ligament repair under SAB. He had history of snoring and a predicted difficult airway. Pre-procedural USG (spine) was done to mark the appropriate lumbar interspace and find the depth of posterior complex (around 73 $\mathrm{mm}$ ). Initial few pricks with long spinal needle (LSN) of Quincke bevel $(25 \mathrm{G}, 120 \mathrm{~mm})$ failed. The needle was found to be bent on removal, so we decided to use a spinal needle as a long introducer for repeat attempt with another LSN. A wide-bore spinal needle was unavailable, so a $18 \mathrm{G}$ spinal needle $(90 \mathrm{~mm}$, Mercury $^{+\mathrm{TM}}$ ) was procured from arthroscopy equipment. After generous infiltration of lignocaine along the needle path, the 18G spinal needle was inserted till it got engaged in interspinous ligaments, taking care to leave around $3-4 \mathrm{~cm}$ outside. The repeat SAB with LSN through the $18 \mathrm{G}$ introducer needle was successful in first attempt (Figure 1). Further anesthetic management and the surgical procedure was uneventful.

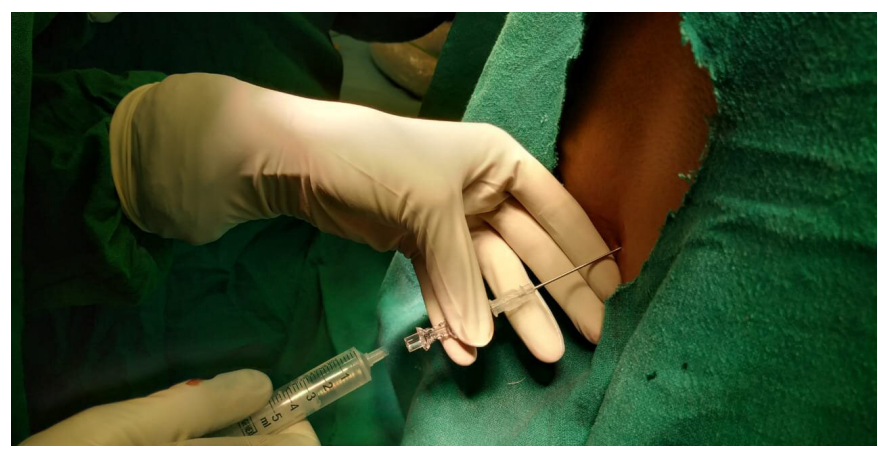

Figure 1: Use of 18G spinal needle as introducer for 25G long spinal needle.

The depth of SAB in morbidly obese patients is often more than the length of conventional spinal needles $(88 \mathrm{~mm})$, leading to multiple blind pricks and failed spinal. LSN are not freely available, their sturdiness is limited by their length and bore size. ${ }^{1}$ During insertion, these LSN may bend and deflect from the intended trajectory leading to failed attempts, needle breakage, and patient discomfort. ${ }^{2}$ This can be decreased significantly with the use of a thick introducer. ${ }^{2,3}$

An introducer needle provided with standard spinal needles to guide the smaller-gauge spinal needles would be noticeably short in obese patients; and may not negotiate beyond the subcutaneous fat. Furthermore, many of the commercially available LSN needles (120-150 mm) are devoid of any introducer needle. A (18-21G) spinal needle may be used as an introducer, but are not widely available. ${ }^{4} \mathrm{~A}$ wide bore needle used by orthopedic surgeons for arthroscopy is suitable, if available. One potential risk of these wide-bore needles is unintentional dural puncture and consequent post-dural puncture headache as dural depth is variable. Pre-procedural USG is, therefore, an important prerequisite to ascertain the dural depth and to infer appropriate choice of spinal needles (LSN or standard spinal needle). ${ }^{5}$

Hence, we conclude that use of pre-procedural or dynamic USG guidance along with use of wide bore spinal needle as an introducer can potentially reduce the puncture attempts and improve overall success of SAB.

\section{PATIENT'S CONSENT:}

Informed consent was obtained from patient to publish the data concerning this case.

\section{CONFLICT OF INTEREST:}

The authors declared no conflict of interest.

\section{AUTHORS' CONTRIBUTION:}

AG: Conceptualisation, data curation, methodology, software, writing original draft, writing review \& editing.

AG: Resources, writing review \& editing.

AG: Material collection, writing review \& editing.

\section{REFERENCES}

1. Sitzman BT, Uncles DR. The effects of needle type, gauge, and tip bend on spinal needle deflection. Anesth Analg 1996; 82(2):297-301. doi: 10.1097/00000539199602000-00014.

2. Kaboré RAF, Traore IA, Traore SIS, Bougouma CTHW, Augustin P, Ouro-Bang'na Maman AF. Broken needle during spinal anesthesia: An avoidable complication. Local Reg Anesth 2018; 11:111-13. doi: 10.2147/ LRA.S175547.

3. Ahn WS, Bahk JH, Lim YJ, Kim YC. The effect of introducer gauge, design and bevel direction on the deflection of spinal needles. Anaesthesia 2002; 57(10):1007-11. doi: 10.1046/j.1365-2044.2002.02657.x.

4. Soto R, Schultetus RR. Using a spinal Needle as an introducer for a spinal Needle. Anesthesiol 2001; 95(3):814. doi: 10.1097/00000542-200109000-00054.

5. Morimoto $Y$, Ihara $Y$, Shimamoto $Y$, Shiramoto $H$. Use of ultrasound for spinal anesthesia in a super morbidly obese patient. J Clin Anesth 2017; 36:88-9. doi: 10.1016/j.jclinane. 2016.10.024. 
Anju Gupta ${ }^{1}$, Amita Gupta ${ }^{2}$ and Aastha Gaba

......................................................................

${ }^{1}$ Department of Anaesthesia, Pain Medicine and Critical Care, All India Institute of Medical Sciences, Ansari Nagar, New Delhi, India

${ }^{2}$ Department of Anaesthesia, Pain Medicine and Critical Care, VMMC and Safdarjung Hospital, New Delhi, India
Correspondence to: Dr. Anju Gupta, R No. 6, 4th floor, Porta cabin, Teaching block, Department of Anaesthesia, Pain Medicine and Critical Care, All India Institute of Medical Sciences, Ansan Nagar, New Delhi 110029, India E-mail: dranjugupta2009@rediffmail.com

Received: July 14, 2020; Revised: August 07, 2020; Accepted: August 11, 2020

DOI: https://doi.org/10.29271/jcpsp.2021.07.873 